\title{
Ehlers-Danlos Syndrome, Type III
}

National Cancer Institute

\section{Source}

National Cancer Institute. Ehlers-Danlos Syndrome, Type III. NCI Thesaurus. Code C125698.

Ehlers-Danlos syndrome, type III is the hypermobility type Ehlers-Danlos syndrome. In most cases, the cause is unknown. Mutations in the TNXB gene have been found in a very small percentage of cases. 